\title{
Formação cidadã de jovens no contexto de um regime democrático híbrido
}

\author{
Young citizen formation in the context of a hybrid democratic regime
}

\section{Rute Vivian Angelo Baquero Marcello Baquero}

\section{Resumen}

O objetivo deste trabalho é analisar o efeito do tipo de construção democrática contemporânea no Brasil, de natureza híbrida, na transmissáo de valores, normas e crenças que estruturam a personalidade política dos jovens porto-alegrenses via processo de socialização política. Híbrido refere-se a uma situação onde os procedimentos poliárquicos estão consolidados, evidenciando uma legitimidade jurídica, que coexiste, simultaneamente, com um déficit de legitimidade social. Nesse cenário, se examina especificamente como os jovens (de 15 a 20 anos) internalizam crenças e valores em relação à política e suas instituiçóes. O pressuposto é de que a formaçáo cidadã dos jovens náo produz o desenvolvimento de atitudes e comportamentos que valorizem os princípios democráticos, gerando uma cultura política de desconfiança, cinismo e passividade. Metodologicamente, são utilizados dados de natureza qualitativa e quantitativa para atingir o objetivo da pesquisa.

\section{Palavras-chave}

Juventude; Socialização Política; Democracia Híbrida; Brasil; Cultura Política.

\section{Abstract}

This paper aims to analyze the effect of the type of contemporary democratic construction in Brazil, of a hybrid nature, in the transmission of values, norms and beliefs that form the political personality of young porto-alegrenses trough the process of political socialization. Hybrid refers to a situation where the polyarchic procedures are consolidated, indicating a juridical legitimacy, that coexists, at the same time, with a social legitimacy deficit. In this context, we examine specifically how young people (from 15 to 20 years old) internalize beliefs and values related to politics and its institutions. The assumption is that the civic education of the youth does not produce the developing of attitudes and behaviors that value democratic principles, generating a political culture of distrust, cynicism and passivity. Methodologically, we use data of qualitative and quantitative nature to reach the goal of this research.

\section{Keywords}

Youth; Political Socialization; Hybrid Democracy; Brazil; Policital Culture. 


\section{Introdução}

O objetivo deste trabalho é analisar o processo de internalização de valores e crenças no contexto político de uma democracia híbrida entre jovens de escolas públicas e privadas de Porto Alegre/RS, de 15 a 20 anos. A hipótese postulada é de que a estrutura da formação cidadá dos jovens no Brasil não conduz ao desenvolvimento de atitudes e comportamentos que valorizem princípios democráticos. Metodologicamente, dados de natureza qualitativa (entrevistas em profundidade) e quantitativa (dados de surveys) são utilizados para alcançar o objetivo do trabalho. Na dimensão quantitativa trabalha-se com amostras estatisticamente representativas de jovens de escolas públicas e privadas de primeiro e segundo grau na cidade de Porto Alegre, Brasil.

O texto está estruturado em quatro partes. Além da introdução, discute-se, na primeira parte, a influência de fatores histórico-estruturais na formação da personalidade política dos jovens brasileiros. A segunda parte examina como os jovens internalizam valores políticos e como esses valores estruturam sua formação cidadá. $\mathrm{Na}$ terceira parte, analisa-se, do ponto de vista empírico, a percepção dos jovens a respeito de conceitos- chave da democracia, tais como eficácia política e participação política. Nas conclusóes, discute-se as implicações dos resultados em termos do papel da juventude no desenvolvimento da democracia no país.

A literatura sobre a desconfiança nas instituições e o declínio dos partidos políticos no Brasil contemporâneo têm produzido uma área cinzenta sobre o futuro da democracia no país (BAQUERO, 2001). Pontualmente, em relação as instituiçóes políticas se argumenta que elas estariam num processo irreversível de comprometimento de sua capacidade de mediação e representação política entre estado e sociedade. Essa situação, no entanto é paradoxal, pois as instituiçóes, especificamente os partidos, continuam a ter o monopólio do recrutamento político e da organizaçáo do Congresso e do governo. Neste sentido, ainda que suas funçóes representativas tenham diminuído, seu papel institucional se mantém intacto, em outras palavras, o fortalecimento dos partidos ocorre simultaneamente com o seu distanciamento da sociedade. Situação semelhante sofre o Congresso, o governo e as instâncias secundárias do sistema político.

A crise das instituiçôes políticas, ao não conseguirem desempenhar suas funções institucionalmente definidas, combinada com o reforço crescente de valores individuais, tem contribuído para que as pessoas "abandonem o mundo político”. Um dos principais componentes dessa deserção dos cidadãos da vida pública e das instituições é a corrupção política institucionalizada. Nessas circunstâncias, o retorno do neopopulismo que busca estabelecer uma relação direta entre cidadãos e estado, à 
margem das instituições formais de mediação política, tem se fortalecido. A este respeito e em relação aos partidos é contundente ao afirmar que:

Hoje em dia os partidos estão em farrapos em todas as partes. As ideologias que possibilitaram aos partidos europeus reunir facçôes diferentes em uma organização, para conquistar e controlar o poder perderam a maior parte de seu poder integrador. Os partidos e seus slogans não fazem sentido para os eleitores, especialmente os mais jovens (DRUKER, 1993, p. 118).

Tal situação é aplicável ao cenário brasileiro onde a decepção da população, especialmente os jovens, com as instituiçóes políticas, em virtude do seu desempenho precário de representação política em tarefas básicas, tais como educação política e a constituiçáo de cidadáos engajados e conscientes do processo político, tem produzido um processo de internalização de valores políticos pouco afeito aos princípios republicanos, resultando em discussóes teóricas sobre o desempenho e a qualidade da democracia. Nesse sentido, na medida em que o regime político brasileiro continua a evidenciar enclaves autoritários a despeito dos avanços formais, ele pode ser identificado como um regime de democracia híbrida. Neste tipo de democracia (BOGAARDS, 2009), aspectos formais da democracia convivem com enclaves autoritários, ou seja, trata-se de sistemas políticos que se situam entre a autocracia e a democracia. O sistema possui os requisitos necessários de igualdade, liberdade e um sistema satisfatório de controle do poder político, necessário ao estabelecimento de uma democracia formal, entretanto, tais sistemas acabam por impor sistemas eleitorais autoritários à sociedade, uma vez que não conseguem sanar os déficits de pobreza e desigualdade social no país. A democracia brasileira, portanto, combina instituiçóes políticas formais consolidadas com índices elevados de desigualdade social (PNUD, 2003).

Identificar as razões que levaram a essa situação é um desafio que se coloca para os cientistas políticos contemporâneos responder. Desse modo, esse trabalho se respalda em duas motivaçóes principais. A primeira, deriva da importância de compreender a dinâmica da construção democrática no Brasil a partir da perspectiva teórica da constituiçáo de uma cultura política de jovens. O pressuposto desta perspectiva é de que um regime é considerado estável quando é congruente com a cultura política prevalecente entre seu povo (ALMOND e VERBA, 1963; ECKSTEIN, 1966). Desse modo, uma democracia é estável quando as pessoas estão convencidas de que os valores democráticos e a instituições se constituem na fonte suprema do poder político. A segunda razáo diz respeito à existência de graus de 
incongruência latente entre valores e tipo de regime, neste caso democrático, que podem persistir por longos períodos produzindo regimes híbridos. Decorre dessa situação a manutenção de um processo de socialização política, especialmente entre os jovens, que não conduz à formação de cidadãos críticos e de uma cultura política participativa.

Nesse contexto de antagonismos sociais, os jovens brasileiros, desde o período da redemocratização, convivem com situaçóes muito diferentes das dos jovens em países desenvolvidos, na medida em que enfrentam problemas sociais como a miséria, a exclusão, o desemprego e a falta de perspectivas em relaçáo ao futuro de suas vidas. A importância da juventude, portanto, para o tipo de cultura política que se estrutura no Brasil passa pela compreensão dos fatores que produzem atitudes e comportamento de apatia e de desinteresse em relação à política desse importante segmento populacional. No Brasil, dados do IBGE (2010) revelam que os jovens são um grupo de destaque - a grande maioria -, sendo que o contingente juvenil, na faixa etária de 15 a 25 anos, atinge 50.492.212 habitantes, o que corresponde a $27,8 \%$ da população brasileira.

A proporção de jovens no cenário brasileiro coloca a educação política e a formação de valores democráticos da juventude num patamar prioritário, direcionadas para a construção de uma cidadania ativa. Este é um dos principais desafios do Brasil. Entretanto, as agências socializadoras (família, escola, grupos de referência, mídia, entre outras) têm sido impactadas pelo acelerado desenvolvimento tecnológico, o processo de globalização e a perda de referentes tradicionais de identidade coletiva, reforçando valores individuais e consumistas, ao invés de incentivar a formação de uma cultura cívica entre os jovens. A prevalência desses traços contemporâneos da cultura política juvenil necessita ser compreendida, numa primeira aproximação, com base nos fatores histórico-estruturais da formação do sistema político no país.

\section{Fatores histórico-sociais que afetam a socialização politica dos jovens}

A Socialização Política se refere ao processo por meio do qual os jovens internalizam normas e valores políticos na formação de sua personalidade política (ALMOND et al., 2008). Nessa perspectiva, é na fase da adolescência em que a maioria das atitudes e comportamentos políticos são adquiridos. Almond et al. (2008) argumentam que a Socialização Política caracteriza-se por três aspectos: (1) a socialização ocorre de forma direta (escolas, programas de governo, informaçóes politicas difundidas dentro de um grupo de interesse) e, indireta (observação do 
comportamento político de adultos e de outras sociedades); (2) a Socialização Política é um processo que ocorre ao longo de toda a vida, ou seja, é a consequência de experiências constantes que modificam as atitudes políticas, sendo que os eventos que ocorrem quando o indivíduo é jovem causam maior impacto e, (3) os padrões de socialização podem provocar unificações - por meio de políticas governamentais que proporcionam coesão cultural - ou divisões na cultura política de um país, que resultam de atitudes políticas de grupos diferentes que se contrapõem aos da sociedade, funcionando como elementos de fragmentação cultural (ALMOND et al., 2008).

Para a efetivação da Socialização Política são necessárias algumas agências que atuem sobre os indivíduos, exercendo influência na formação das atitudes e comportamento político. As principais instituiçóes são a família, a escola, as instituições religiosas, grupos de pares, classe social, grupos de interesse, partidos políticos e meios de comunicação. $O$ papel desses agentes é igual em diferentes culturas políticas, entretanto, cada cultura política apresenta sua própria dinâmica de transmissão de valores políticos, dependendo de sua evolução histórica e o grau de desenvolvimento político.

Um dos primeiros autores que tratou de caracterizar a cultura política brasileira foi Sérgio Buarque de Holanda (1936), para quem o Brasil é herdeiro de uma nação ibérica e de uma cultura personalista, onde os vínculos pessoais têm sido decisivos nas relações sociais e políticas. Para o autor a história política brasileira se caracterizaria pelo predomínio de sentimentos particularistas, e pela falta de distinção total entre Estado e família, no qual aquele é visto como uma extensão desta.

Em tal cenário, o desafio dos intelectuais da época era saber como incidir em transformações profundas em um país no qual eram mantidos os fundamentos tradicionais da situação que se queria superar (Holanda, 1995). Seria necessário transformar as relações políticas que insistiam em manter traços arcaicos herdados da colonização portuguesa e do império. $\mathrm{O}$ conceito utilizado por Holanda para descrever a preocupação das elites em manter uma aparente harmonia e de sua capacidade de reagir com violência quando os acordos informais não funcionavam, era a cordialidade. Esse conceito, por um lado, mostra o pacifismo, a hospitalidade e a generosidade do homem brasileiro e, por outro lado, mostra a ausência de um ordenamento impessoal que caracteriza o Estado burocrático e que funciona como elemento estruturador de uma cultura política clientelista. Para Buarque de Holanda, enquanto persistirem esses traços tradicionais, a democracia é um objetivo dificilmente alcançável. 
$\mathrm{Na}$ década de 1950, Raymundo Faoro (1989) sugeria que era o patrimonialismo o principal eixo da cultura política brasileira. Para Faoro, desde a chegada da Coroa portuguesa ao Brasil, surgiu um Estado de natureza patrimonial, cuja estrutura estamental gerou uma elite dissociada da nação, em outras palavras, consolidou-se o patronato político brasileiro que se transformou, ao longo do tempo, em um "estamento burocrático" que privilegiava interesses particulares em detrimento de interesses coletivos. $\mathrm{O}$ sistema patrimonial coloca os cidadãos em uma rede patriarcal na qual eles representam a extensão da casa do soberano. $O$ patrimonialismo se caracteriza pela utilização da propriedade pública para fins privados, onde ocorre uma indistinção total entre o Estado patrimonial e a família patriarcal. Para Weber (2004), em seu livro "Economia e Sociedade", o patrimonialismo se refere a formas de governo que são baseadas na matriz da casafamília de quem manda. Desta forma, a autoridade do governante é patronal-familiar, e a mecânica da casa é o modelo de administração política. A dominação patrimonial é um caso especial de dominação patriarcal que contrasta com o modelo ideal de Weber de burocracia racional-legal, a qual é comandada por atores impessoais e substituíveis. Contudo, no atual contexto se fala de um patrimonialismo ou neopatrimonialismo quando, apesar da existência de procedimentos poliárquicos, continuam a se implementar políticas que dão privilégios às minorias influentes, concedendo-se imunidade a quem atua em desacordo com a lei, e se institucionaliza uma política que se materializa no ditado "é dando que se recebe".

$\mathrm{Na}$ medida em que a apropriação do cargo se dá via burocracia local, o patrimonialismo dá lugar ao coronelismo, que é uma forma peculiar de manifestação do poder privado dentro de uma extensa rede de clientelas. A esse respeito, Vitor Nunes Leal (1978), principal referência desta tese, sugere que não é possível compreender o fenômeno do coronelismo sem fazer referência à estrutura agrária do país, a qual favorece as manifestaçóes do poder privado no interior do Brasil. O coronelismo, portanto, se refere a um "compromisso, uma troca de favores, entre o poder público progressivamente fortalecido, e a influência social decadente dos chefes sociais, principalmente os senhores de terras" (LEAL, 1978, p. 20).

A existência de estruturas oligárquicas e de personalização do poder, o mandonismo e a falsificação do voto, a desorganização dos serviços públicos locais são características do sistema coronelista. Os coronéis faziam favores pessoais de toda ordem, desde conseguir emprego, até escrever cartas ou recibos. Levavam os eleitores para votarem em seus candidatos (voto de cabresto), em troca, o governo estatal disponibilizava dinheiro, empregos e favores em geral aos coronéis. Se o coronelismo declinou significativamente em virtude da crescente industrialização, do aumento do 
eleitorado urbano, da expansão dos meios de comunicação e transportes, a estrutura agrária se manteve intacta.

Em tais circunstâncias, o clientelismo surge como decorrência do coronelismo. Este fenômeno é mais amplo e atravessa toda a história política do país. É um tipo de relação que envolve a concessão de benefícios públicos entre os atores políticos. O clientelismo aumentou com o fim do coronelismo, quando a relação passa a ser diretamente entre políticos e setores da população sem a intermediação do coronel, que perdeu sua capacidade de controlar os votos da população. Na vigência do coronelismo o controle do cargo público era visto como importante instrumento de dominação e não como simples empreguismo. $\mathrm{O}$ emprego público irá adquirir importância como fonte de salário nas relações clientelísticas (CARVALHO, 1997 e 2000). Para Souza (1976), o clientelismo não se constitui necessariamente numa característica da política brasileira ou como uma etapa de desenvolvimento, mas sim como um instrumento de controle de recursos políticos e de sua utilização pelos partidos políticos, buscando dessa forma não somente o poder para eles, mas o reconhecimento de seu poder pela população enquanto instituições legítimas de mediação política.

Ao refletir sobre essas questões, o antropólogo Roberto DaMatta (1993) argumenta que no Brasil o espaço da "casa" se reproduz e se instrumentaliza dentro dos espaços públicos, propiciando com que alguns elementos autoritários fiquem tão arraigados dentro da cultura política que, muitas vezes, não são vistos como assuntos políticos importantes. A naturalização desses elementos, de acordo com DaMatta, está relacionada a problemas culturais e históricos profundos, entre os quais o autor destaca quatro: (1) no Brasil, a persistência do clientelismo e do personalismo tem raízes profundas; (2) a força do familismo e do espaço social da casa é diretamente proporcional à ausência da confiança na vida pública; (3) as relaçóes têm muito mais peso e importância do que as leis e as normas; e (4) as tradiçóes jurídica e política são altamente centralizadoras. Esse quadro favorece a continuidade de uma situaçáo perversa do ponto de vista da cultura política democrática.

Nessa linha de raciocínio, Reis (199 e 1998) considera aplicável ao caso brasileiro o conceito de "familismo amoral" de Banfield, o qual corresponde a um ethos da lógica familista privada, a qual exclui qualquer tipo de solidariedade fora do círculo familiar. De acordo com a autora 
[...] a situação retratada por Banfield sugere que a falta de confiança generalizada leva os membros de uma comunidade a considerar regressar para a esfera privada como seu domínio mais racional. A existência desta característica propicia que em sociedades como a brasileira existam dificuldades para estabelecer a confiança interpessoal e a solidariedade social na medida em que disparidades agudas nas experiências de vida geram diferenças tão grandes nas orientações cognitivas que sentimentos de pertencer a uma comunidade simplesmente não conseguem se institucionalizar (REIS, 1995, p.121).

Em análises recentes da política brasileira, Edson Nunes (1997) identificou quatro gramáticas políticas que caracterizam o país, ao longo da história: o clientelismo, o corporativismo, o insulamento burocrático e o universalismo de procedimentos. Nunes define o clientelismo como um sistema de intercâmbios generalizados e pessoais, caracterizado por situaçóes que implicam combinações de desigualdade e assimetria de poder. A desigualdade desempenha um papel chave na sobrevivência, tanto de patrôes como de clientes e gera uma série de laços pessoais entre eles, que vão desde o simples "compadrismo" até a proteção e lealdade política.

O clientelismo e o corporativismo constituem uma gramática personalista, com base nas relaçóes pessoais com padrões institucionalizados de poder político. As relações pessoais e hierárquicas foram cruciais para a obtenção de favores políticos, transformando as instituições do Estado em mecanismos ou instrumentos de troca de favores. Com a institucionalizaçáo da racionalidade burocrática e de normas com base em relaçóes impessoais, o universalismo de procedimentos e o insulamento burocrático acabam funcionando como medidas de proteção contra o abuso do poder do Estado e se apresentam como gramáticas políticas alternativas ao clientelismo. Não é por acaso que neste contexto o personalismo impregnou as redes de relaçóes sociais e as instituições políticas contemporâneas, mas como essas relações são tratadas como elementos informais e fluídos, são, de maneira geral, ignorados por cientistas políticos.

O clientelismo político moderno foi constatado em certos centros urbanos como Sáo Paulo com o "malufismo" e no Rio de Janeiro com o "chaguismo". Segundo Eli Diniz (1982), as práticas clientelistas evoluíram inseridas em uma organização complexa, a máquina "chaguista", articulando várias redes de clientelas estruturadas em volta de políticos com muita experiência em suas respectivas áreas de atuação. Tal situação é corroborada por Avelino Filho (1991), para quem a grave situação social contemporânea tem sido amenizada pelos programas sociais paternalistas e compensatórios, os quais têm contribuído para o círculo vicioso do 
sistema político - sociedade desigual e práticas clientelistas. Ao mesmo tempo, outro elemento que contribui para manter uma cultura política clientelista no Brasil é o sistema eleitoral de representação proporcional com lista aberta, que concorre para que o eleitor se centre muito mais no candidato do que no partido. A consequência é que uma vez eleitos, os políticos não são fiscalizados eficientemente pelos partidos e, dessa forma, detém ampla autonomia para trocar de partido com muita facilidade (SAMUELS, 1997).

Tais elementos históricos do Brasil mostram uma tendência preocupante de escândalos políticos como característica estrutural da formação política do país. Está além dos objetivos deste artigo fazer um levantamento de todas as ocorrências, embora seja possível identificar, na última década (2001-2010), alegações de corrupção na compra de votos pelos partidos no poder, a prevalência de serviços públicos deficientes, o crescimento da violência e a expansão da pobreza e da exclusão social. Essas ocorrências dentro de um contexto de democratização geraram perplexidade, pois "poucos esperavam que a fragmentação política e o subdesenvolvimento institucional se tornariam desafios" de uma crise permanente de governabilidade (AMES e POWER, 2006, p.1).

A este respeito, Payne et al. (2002) apontam o elevado índice de fragmentação partidária do país (6.70), sendo que o número efetivo de partidos no Brasil é o dobro da média de outros países. O Brasil é caracterizado, assim, como uma nação pouco institucionalizada em temos de partidos políticos (MAINWARING e SCULLY, 1995). Em estudo desenvolvido por Ames e Power (2006), o sistema partidário é descrito como sendo altamente fragmentado, competitivo, volátil e com uma institucionalização frágil.

A fragmentação política da sociedade brasileira, portanto, deriva de enraizamentos históricos e culturais de práticas clientelistas e corporativas, que têm impedido a coesão desejada. O descrédito das instituições políticas não tem impedido que o clientelismo, o personalismo e o patrimonialismo nas suas versóes neo, continuem sendo elementos articuladores preponderantes da política do Brasil.

Desse modo, as dimensóes histórico-estruturais como o patrimonialismo, o clientelismo, o "familismo" e o personalismo geram uma assimetria temporal na qual não há uma compatibilidade entre a democracia e as atitudes dos cidadãos, que se orientam muito mais por motivaçóes subjetivas e emocionais. Situaçóes como esta possibilitam o surgimento, no atual contexto, do que tem sido denominado de teoria do desgoverno (SANCHES PARGA, 2001) na qual a governabilidade serve apenas para tornar "governável o desgoverno", fruto das políticas públicas assistencialistas e 
que incidem diretamente em três dimensões: (1) na exclusão e o empobrecimento de vastos setores da população; (2) na corrupção institucionalizada; e (3) na violência.

Em síntese, a existência de um sistema político socialmente frágil no Brasil é atribuída, por grande parte da literatura sobre a democracia, ao corporativismo, ao clientelismo, à estrutura centralizada do Estado, à oligarquização do jogo político, à ausência da participação política e à falta de uma legitimidade político-partidária no processo de construção democrática (MAINWARING, 2001).

A fragmentação e atomização da sociedade civil, características da política no Brasil também têm problemas que limitam severamente a democratização. Tanto a evidência histórica como empírica sugerem que o clientelismo, o personalismo e o patrimonialismo têm plantado raízes profundas no tipo de cultura política que se constitui por meio do processo de transmissão de uma geração para outra de valores que não propiciam o fortalecimento $\mathrm{da}$ democracia, entendida num sentido substantivo. Esse processo é reforçado por mecanismos eleitorais que promovem o personalismo e o clientelismo. Assim, o regime político no Brasil é democrático, mas não consegue promover a construção de uma cultura política politicamente engajada por não conseguir diminuir a influência de uma política personalista. É neste cenário que assume relevância compreender como os jovens estruturam suas atitudes e comportamento político.

\section{Juventude e formação cidadã}

A participação dos jovens é reconhecida como questão importante desde os clássicos. Uma leitura atenta dos escritos de Platâo mostra sua preocupação na compreensão do papel do comportamento humano na dimensão política. No livro $A$ República, Platão (1955) examinou a necessidade de inculcar nos jovens aquelas qualidades humanas que, segundo ele, eram necessárias para o desenvolvimento de bons políticos. Por sua vez, Aristóteles (1990), na obra A Política, mostrou a importância de elaborar as constituiçóes dos países espelhadas no caráter de sua população. Tocqueville (1977) argumentava que não haveria democracia se não houvesse cidadãos e estes, não existiriam, se não se interessassem por política. Pesquisas, nas décadas de 1990 e 2000 (SPOSITO, 2003; DWYER et al., 2014), têm enfatizado a importância de estudar o papel da juventude na sociedade contemporânea, destacando a necessidade das investigações examinarem os novos padrôes culturais juvenis (SPÓSITO e CORTI, 2002).

Especificamente o tema "jovens e participação política”, que demarcou a produção das Ciências Sociais no Brasil, na década de 1960, têm, paradoxalmente, fraca presença nos estudos educacionais sobre juventude, tendo sido localizados 
somente 23 trabalhos, no período 1980-1988, conforme análise desenvolvida por Carrano (2002). Tais trabalhos se centraram, basicamente, na análise da participação política do jovem estudante, suas práticas, valores e representações, a partir dos modelos observados nos anos 1960 e 1970. Os trabalhos, de natureza histórica, buscam recuperar as mobilizaçóes estudantis durante a ditadura militar. Por outro lado, o autor refere um outro tipo de participaçáo juvenil, relacionado a um novo contexto político de afirmação da cidadania, presente principalmente nos anos 1990 . Trata-se de pesquisas que investigam os motivos pelos quais os jovens se envolvem ou deixam de se envolver em questóes de organização social e política, focalizando questóes relativas a aspectos de socialização política e do desenvolvimento da cidadania. A investigação sobre estas questôes é bastante incipiente no campo da Educação e Política e ainda merecem, nas palavras de Carrano (2002, p. 198), "Um conjunto de estudos de modo a compreender os vários formatos em que a presença política dos jovens deixa de ocorrer ou aparece de modo bastante tímido na sociedade brasileira no final dos anos 1990 ".

Estudos sobre a educação política tratam de uma dimensão importante da formação humana juvenil, pois envolvem conhecimentos e habilidades cívicas, predisposições e atitudes em relação à participação social e política, crenças e valores em relação à democracia em si e lida com questôes com implicações não só para a prática educacional, mas também para a prática política no país.

A relação entre educação e democracia, segundo Baquero (2004), é controversa. Apoiada em Villegas-Reimers (1995), a autora refere que, muitas vezes, países com populações com altos níveis de escolarização têm se afastado do regime democrático, revelando que nem todo tipo de educaçáo é garantia de democracia. Nas palavras de Villegas-Reimers (1995, p. 52): "De hecho, en los países con regímenes más opresores se encuentra que la educación ha sido utilizada como herramienta de esa opresión".

No entanto, Rifkin (1999) assinala que a maioria dos estudos demonstra que não há democracia sem educação, ou seja, não existe um país democrático com uma população não educada. Desse modo, embora a educação seja necessária, ela não é condição suficiente para a existência de uma democracia. Não existe na literatura, de acordo com Rifkin (1999), estudo empírico sobre os efeitos da educação na democracia latino-americana. No entanto, estudo desenvolvido por Garay e Schvartzman (1987) evidencia o pouco conhecimento que os cidadãos latinoamericanos - paraguaios - têm sobre a vida democrática. Resultados de entrevistas realizadas com cerca de 2000 pessoas entre 19 e 24 anos de idade revelam que: somente $33 \%$ dos entrevistados disse que um componente básico de ser cidadáo é ter 
direitos políticos; $33 \%$ não sabia o que era a Constituição; somente $66 \%$ sabia o que era votar e, embora a grande maioria valorizasse o direito de livre expressão, 40\% disse que o governo não deveria ser criticado, pois os governantes sempre sabiam o que faziam ou porque criticar o governo era um comportamento subversivo.

A pesquisa de Méndez et al. (1989) identificou resultados similares em países latino-americanos com uma tradição democrática, como a Venezuela, onde cerca de $70 \%$ dos entrevistados não tinha conhecimento dos seus direitos constitucionais mais básicos. Pouco conhecimento e muito baixo interesse pela vida democrática é referido por Rodriguez $(1987,1989)$ em pesquisas realizadas também em países latinoamericanos - Argentina, Uruguai, Paraguai, Costa Rica, Venezuela, Colômbia, Peru e Nicarágua.

Esses dados têm levado os pesquisadores a questionarem, que tipo de educação política é necessária. Conforme Villegas-Reimers (1995, p. 52) destaca: "Entonces no es que cualquier educación es deseable; es que tiene que haber un tipo particular de educación que prepare a los ciudadanos para vivir en democracia [...] Hace falta educar para la democracia explicitamente".

Estudiosos como John, Halperr e Morris (2001) têm indicado que grande parte da pesquisa existente nos Estados Unidos e na Inglaterra a respeito do impacto de educação cívica conta, como evidência, com poucos dados quantitativos. Além disso, segundo esses autores, o estado da arte reflete a história do ensino deste tema e advertem que não há grande tradição no ensino da educação para a cidadania nas escolas inglesas ou de trabalho voluntário e serviço comunitário para os jovens. No Brasil, na época de ditadura militar, educação política foi desenvolvida como educação moral e cívica.

Por outro lado, de acordo com Blair (2003), relativamente pouco conhecimento se tem a respeito dos efeitos de programas de educação cívica. Mesmo nos Estados Unidos, onde a educação cívica já tem uma tradição no sistema educacional, resultados de pesquisas revelam que seus efeitos incidem em somente duas dimensões - competência democrática e valores democráticos -, dentre as três dimensões que constituem as características essenciais do que uma participação cidadã numa democracia deve envolver, não influenciando, portanto, na dimensão do comportamento democrático.

Competência democrática envolve conhecimento sobre política, habilidades cívicas e senso de eficácia política. Valores democráticos dizem respeito, dentre outros, à tolerância a pontos de vista divergentes e suporte a políticas democráticas. Comportamento democrático, por sua vez, está relacionado com a participação política, em nível local e nacional. A participação dos jovens em atividades da 
organização estudantil repercute na vida em comunidade do estudante, que se envolve em associações e outras formas de interação social, criadoras de capital social. Tal envolvimento tem efeitos na socialização política do jovem, "ampliando a aquisição de normas e valores cooperativos, bem como de confiança necessária para o funcionamento adequado da democracia. As associações funcionam como escolas para se aprender democracia" (STOLLE e HOOGHE, 2002, p.3).

No entanto, é necessário salientar que a educação política para uma convivência democrática não se inicia no processo de escolarização. Ela está presente, muito cedo, na vida das pessoas, influenciando nos seus padróes de comportamento social e político.

Em relação a essa questão, três modelos de socialização política são referidos por John, Helper e Morris (2001). Inicialmente, destacam o modelo desenvolvido no período clássico do estudo de socialização política (década de 1970), o qual argumenta que o status socioeconômico constitui importante determinante das atitudes em relação à política, o que, no contexto dos estudos sobre a juventude, pode ser expresso como status socioeconômico intergeracional. Uma abordagem complementar a esse modelo postula que as orientaçóes e ações cívicas dos pais se transferem para a outra geração.

No primeiro caso situam-se os estudos de Milbraith e Goel (1977) e Almond e Verba (1989), entre outros. Em relação à segunda abordagem, os estudos de Beck Jennings (1982) e de Dowse e Hughes (1971) revelam que pais com atitudes positivas em relação à democracia e histórias de participação tendem a transferir, para seus filhos, atitudes semelhantes.

Já na década de 1990 a pesquisa sobre o tema revela que há outros "caminhos" para a socialização política, além do "background" social e familiar; tratase da influência dos meios de comunicação e dos pares nesse processo. Além disso, a abordagem desenvolvimentista no processo de socialização, assumindo o que Flanagan e Sherrod (1998) denominam de "plasticidade ao longo da vida", tende a relativizar o poder de mecanismos de natureza intergeracional na transferência de comportamentos e valores nesse campo e hipotetiza que a escola e o currículo podem, sob certas condiçóes, influenciar atitudes e comportamentos cívicos desejáveis.

Recentemente, os trabalhos de Putnam (1996 e 2000) sobre capital social têm, dentre outros aspectos, ampliado o escopo do estudo sobre participação política. $\mathrm{O}$ autor atribui um peso significativo às redes na modelagem de atitudes e comportamento político e ao comportamento associativo, os quais consistiriam em dimensóes menos convencionais da sua determinação. Subjacente ao conceito de capital social está o modelo de um "cidadão virtuoso", que vota, obedece a lei e se 
envolve em trabalho voluntário. Dessa forma, a existência (ou não) de estoques de capital social se constitui também em medida importante no processo de educação política do jovem.

Os modelos teóricos prevalecentes sobre socialização se assentam sobre os seguintes princípios: o princípio da primazia - a aprendizagem de criança dura toda a vida e o princípio da estruturação - as orientações básicas adquiridas durante a infância estruturam a aprendizagem posterior de crenças sobre assuntos específicos (BAQUERO, 1997).

Dessa forma, seja qual for o modelo utilizado, há um consenso de que os valores e normas internalizadas pelas crianças são importantes como determinantes das atitudes quando adultos. Subjacente a esse pressuposto está a ideia de que aquilo que se aprende na infância dificilmente será deslocado para experiências posteriores. Nessa perspectiva, o comportamento adulto tende a revelar uma certa consistência com aquilo que se aprende na infância e na adolescência.

O princípio da primazia liga os valores internalizados na adolescência a orientaçóes quando adultos, enquanto o principio da estruturaçáo exige uma identificação das variáveis que estruturam uma crença a partir do princípio $d a$ primazia.

Quando as crianças alcançam o início da adolescência e chegam à fase préadulta, seu sistema de crenças já está enraizado. A partir daí, essas crenças sofrem um processo de diferenciaçáo face à exposição aos meios de comunicaçáo, a novos grupos de referência e ao impacto de eventos conjunturais (desemprego, qualidade de vida) no cotidiano das pessoas.

Basicamente, portanto, o comportamento social e político é resultado de um processo de aprendizagem e essa aprendizagem começa na infância e, em muitos sentidos, é complementada na adolescência (SIEGEL, 1989).

\section{Análise dos resultados}

A primeira dimensão examinada diz respeito a como os jovens decodificam o conceito de democracia. Num segundo momento, são apresentados dados a respeito da predisposição para participar e a participação propriamente dita por parte dos jovens em ações de natureza democrática tanto na escola, quanto fora dela.

Os depoimentos dos jovens a respeito do seu entendimento sobre democracia revelaram que, de maneira geral, percebem a democracia num sentido difuso, como algo positivo, uma forma ideal de um sistema político:

"Democracia é a melhor forma de governar".

"Na democracia todos somos iguais". 
“A democracia é o governo do povo".

Os dados indicam também, que os jovens divergem sobre o significado de democracia: se dividem entre os que a veem na dimensão formal ("democracia é votar"; "na democracia tem leis") e aqueles que a concebem na dimensão de conteúdo ("na democracia o povo tem as coisas para sobreviver"). Alguns equacionaram democracia com liberdade ("na democracia a gente pode falar"), outros com ordem ("na democracia tem que obedecer as leis"), outros, ainda, com igualdade ("na democracia tem direitos").

A partir dessa valorizaçáo positiva da democracia analisaram-se dados de natureza quantitativa referentes à eficácia política, ou seja, o senso que os jovens têm de que sua participação pode influenciar no processo decisório.

Para medir a eficácia política no âmbito escolar solicitou-se a opinião dos jovens sobre a importância de participar nas decisóes escolares. Os dados apresentados revelam que $89 \%$ dos jovens em 2001, 79\% dos jovens em 2004 e 77\% em 2010 (Gráfico 1) consideram importante sua participação nas decisões escolares, evidenciando uma predisposição positiva de eficácia política entre eles. $\mathrm{Na}$ dimensão atitudinal, portanto, coerente com o princípio difuso de valorização da participação, pode-se afirmar que os jovens porto-alegrenses detêm um potencial de mobilização elevado.

Gráfico 1 - Predisposição positiva dos jovens em participar nas decisões escolares

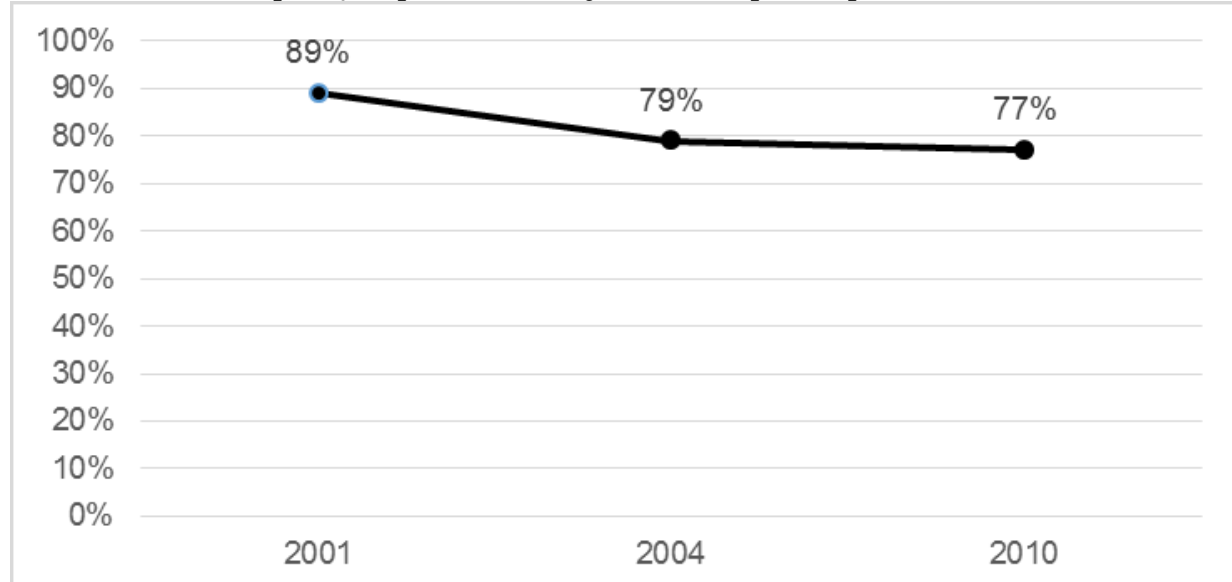

Fonte: Pesquisa Capital Social e Juventude (NUPESAL, 2002 e 2004) e IEL/CNI, 2010.

Com relação à predisposição dos jovens para a participação política, os dados indicam que 53\% dos jovens em 2001, 65\% em 2004 e 61\% em 2010 consideram importante a sua participação em atividades políticas (Gráfico 2), entretanto os dados 
74 | Rute Vivian Angelo Baquero e Marcello Baquero

revelam níveis mais baixos de predisposição para participar na esfera pública quando comparados com a esfera escolar. Estes dados sugerem que à medida em que os jovens se aproximam de iniciativas mais pontuais e próximas da esfera política, seu interesse em se engajar nessas atividades declina substancialmente.

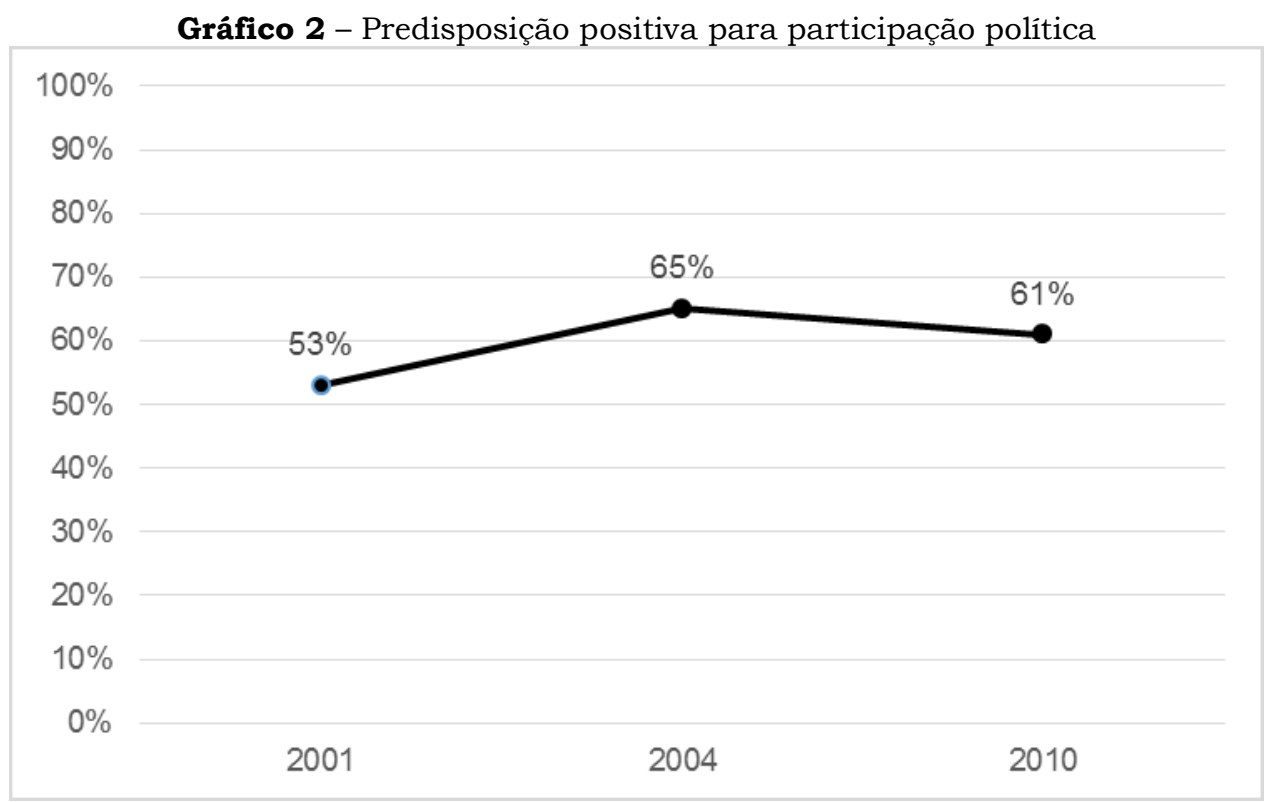

Fonte: Pesquisa Capital Social e Juventude, (NUPESAL, 2002 e 2004) e IEL/CNI, 2010.

A predisposição negativa em relação a participar na política é congruente com predisposiçóes dessa natureza identificadas em nível da escola. Indagados sobre sua participação em atividades do Grêmio Estudantil constata-se que $62 \%$ dos jovens em 2001, 64\% em 2004 e 71\% em 2010 declaram não participar nessas atividades (Gráfico 3). Tais respostas indicam que uma das agências centrais de formaçáo da personalidade política dos jovens - a escola - não consegue estimular os alunos a se engajar em atividades do órgão que representa seus interesses junto à direção da escola. A escola, portanto, nos anos examinados, não se constitui em organismo pedagógico do exercício participativo, nem em mecanismo de construção de valores orientados para a valorização das instituições de mediação política. A situação se agrava quando os jovens foram indagados sobre sua participação em grêmios estudantis, que se situa abaixo de $29 \%$ nos anos examinados. 
Gráfico 3 - Não participação dos jovens em atividades do Grêmio Estudantil $100 \%$

$90 \%$

$80 \%$

$70 \%$

$60 \%$

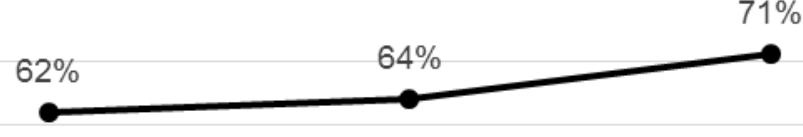

$50 \%$

$40 \%$

$30 \%$

$20 \%$

$10 \%$

$0 \%$

2001

2004

2010

Fonte: Pesquisa Capital Social e Juventude (NUPESAL, 2002 e 2004) e IEL/CNI, 2010.

Da mesma forma, no que se refere à discussão dos problemas da escola com os colegas, há uma inclinação dos jovens para o debate, no entanto, isso não ocorre de forma sistemática. Os jovens que discutiam os problemas da escola foram $54 \% \mathrm{em}$ 2001; 42\% em 2004 e 47\% em 2010, revelando uma diminuição de interesse dos alunos, ao longo dos anos, em encontrarem soluções em conjunto para qualificar a escola (Gráfico 4). 
76 | Rute Vivian Angelo Baquero e Marcello Baquero

Gráfico 4 - Discussão dos problemas da escola com os colegas

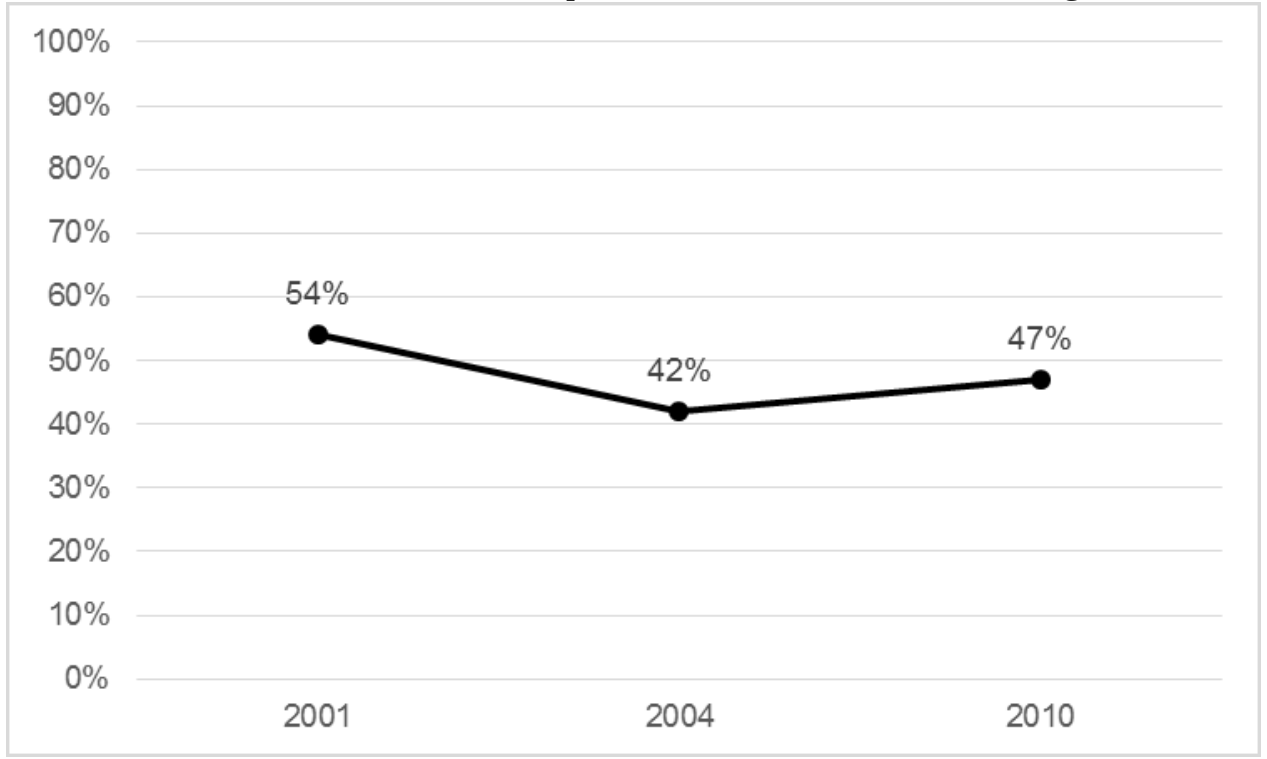

Fonte: Pesquisa Capital Social e Juventude, (NUPESAL, 2002 e 2004) e IEL/CNI, 2010.

No que diz respeito à participação em atividades fora do âmbito escolar, os dados são mais contundentes: 55\% dos jovens em 2001; 58\% em 2004 e 67\% em 2010 náo costumam participar de nenhum tipo de atividade política, e, quando participam, os índices estão um pouco acima de 10\% (Gráfico 5).

Gráfico 5 - Participação política

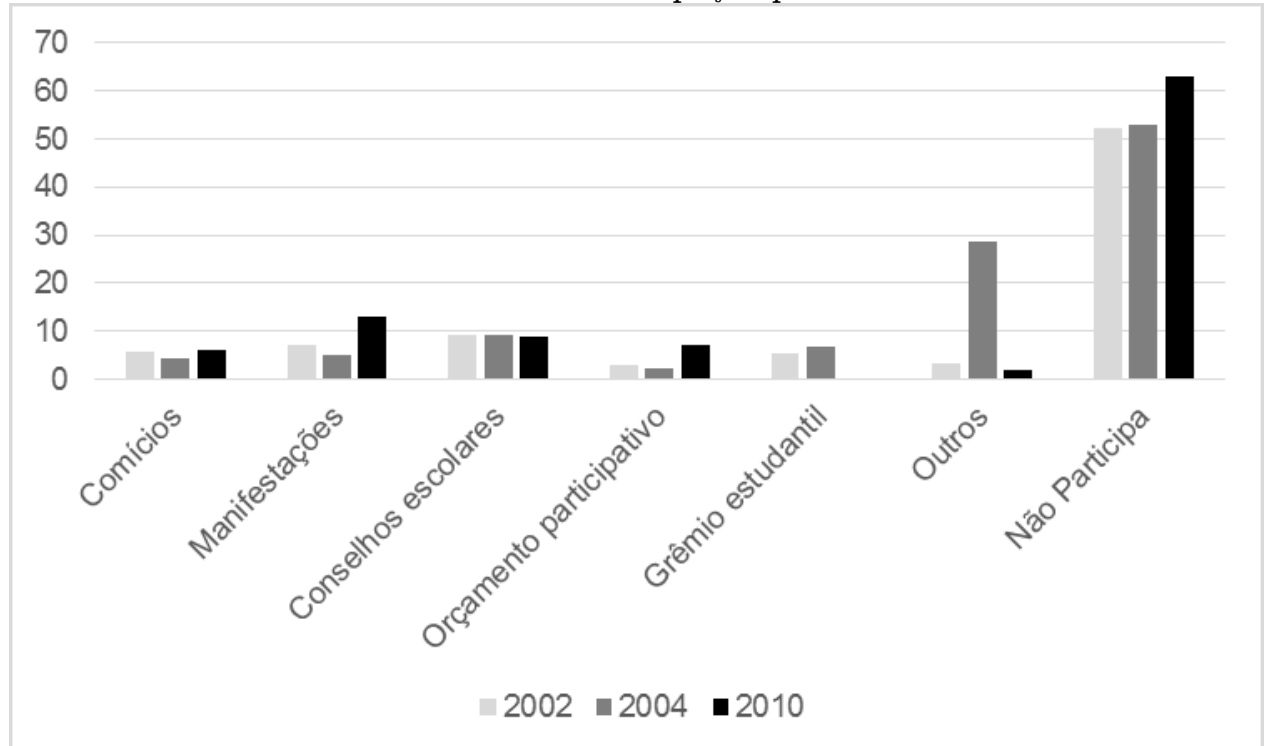

Fonte: Pesquisa Capital Social e Juventude, (NUPESAL, 2002 e 2004) e IEL/CNI, 2010. 
Os resultados aqui apresentados corroboram dados da pesquisa desenvolvida por Souza (1983) em Porto Alegre, que concluiu que, embora a democracia seja valor para os jovens, a estrutura escolar centralizada náo tem oportunizado situaçóes para o debate e a participação nas decisóes escolares, não estimulando padrôes de comportamento democrático.

Resultados semelhantes são relatados também por Nazzari (1995), em estudo sobre a socialização política de jovens paranaenses, e Baquero (1997), em pesquisa com adolescentes gaúchos. Nazzari (1995) constatou que os jovens paranaenses têm vago conhecimento sobre os problemas nacionais e carecem de valores democráticos fundamentais como a confiança nas pessoas e nas instituições. Baquero (1997) observou, por parte dos adolescentes gaúchos, a tendência à descrença e ao ceticismo em relação à política e aos valores democráticos, apesar de manifestarem um sentimento favorável à democracia de forma abstrata.

Schmidt (2001), em estudo sobre juventude e política no Brasil, salienta que:

Há uma série de traços que se repetem nas pesquisas localizadas em diversos pontos geográficos do Brasil: preferência pela democracia num sentido abstrato, baixa eficácia política, descrença nos políticos e nas instituiçôes, sensibilidade para as idéias de mudança mas sem orientações ideológicas definidas, pequena participação política efetiva (SCHMIDT, 2001, p. 209).

Entretanto, comportamentos sociais e políticos se aprendem. Conforme o mesmo autor:

O ser humano é fruto das circunstâncias sociais e de suas opçôes pessoais. Comportar-se como sujeito ativo ou como indivíduo politicamente passivo tem muito a ver com a própria trajetória. O processo de constituição das atitudes políticas condiciona o comportamento. O caráter democrático não é inato, é construído (SCHMIDT, 2001, p. 17).

A análise dos padrões de comportamento social e político dos indivíduos não pode se dar, no entanto, de forma desvinculada de uma compreensão das múltiplas relaçóes do sujeito com o mundo, uma vez que o processo de socialização é um processo datado e localizado.

Conforme Sandoval (2002), vem ocorrendo mudanças radicais na cultura contemporânea que estaria passando de um modelo cultural baseado na razão social (é legítimo aquilo que é útil à coletividade, ou seja, contribui ao seu progresso e obedece à sua razão) a outro, fundado na auto-realizaçâo autônoma (é legítimo aquilo que o 
indivíduo julga bom para o seu desenvolvimento pessoal). A auto-realização autônoma é o eixo de sustentação do funcionamento do modelo neoliberal, constituindo-se o êxito no mercado o caminho para alcançá-la. Os comportamentos juvenis aqui analisados parecem orientar-se com mais frequência pela lógica da autorealizaçáo autônoma.

\section{Considerações Finais}

Este artigo teve como objetivo central avaliar o processo de socializaçáo política de jovens estudantes de escolas públicas e privadas de primeiro e segundo grau de Porto Alegre/RS na formação de sua personalidade política.

Os resultados mostraram que a forma como os jovens internalizam normas e valores na política coloca em questionamento a naturalização do processo de educação para a cidadania vivenciados pelos jovens, particularmente os processos de educação formal e sua contribuição para a formação de sujeitos democráticos.

Em relação a esta questão, Freire $(1986,2001)$ proporciona uma contribuição fundamental ao problematizar a educação como prática de emancipação. Isto, no nosso entender, é essencial para empreender esforços de educar para a democracia. Uma açáo pedagógica como prática para a emancipaçáo exige o desenvolvimento de um pensamento crítico, o que implica, necessariamente, segundo Freire (2001), o desenvolvimento da "curiosidade epistemológica". A "curiosidade epistemológica" "se caracteriza como inquietação indagadora, como inclinação de desvelamento de alguma coisa, como pergunta verbalizada ou não, como procura de esclarecimento, como sinal de atenção que sugere alerta (...)" (FREIRE, 1986, p. 35).

Gentili (2000), por sua vez, ao questionar qual educação para qual cidadania, numa reflexão sobre a formação do sujeito democrático, afirma que a formação da cidadania supóe a possibilidade de criar espaços educativos nos quais os sujeitos sociais sejam capazes de questionar, de pensar, de assumir e também de submeter à crítica, não somente os valores, normas e direitos morais de indivíduos, grupos e comunidades, mas também os seus próprios valores.

No que diz respeito especificamente à influência do processo de escolarização, muito frequentemente os sistemas educativos através de seus atores, programas e planos têm enfatizado uma educação para democracia, onde o sujeito político construído é aquele ao qual se atribui um ethos individualista, engendrado pelo pensamento democrático liberal no contexto de um Estado de Direito (BOBBIO, 2000). A escola, em geral, não tem contribuído para o desenvolvimento de uma cultura mais solidária, privilegiando, em suas práticas, o individualismo e a competitividade como modo de inserção na sociedade. Essa situação coloca em 
questionamento como promover uma educação para a democracia com vistas à formação de um sujeito político ético, solidário, comprometido com o bem comum, com competência para um protagonismo responsável. Gadotti (1985) sinaliza com uma direção ao referir que:

Mede-se [...] uma educação popular e democrática pela capacidade que ela tem de acolher criticamente os problemas da sociedade, pela capacidade dos educadores de escutarem criticamente esses problemas, para identificá-los, equacioná-los, responder a eles. Concretamente o que fará com que nossos planos de estudo, nossos programas tenham algum valor $[. .$.$] será [. .$.$] a vinculação desse "dizer" com esse povo [...] nosso$ [...] (GADOTTI, 1985, p. 85).

O desenvolvimento da cidadania durante a modernidade parte da definição das bases do contrato social e da sua instituição mantenedora, o Estado. Para efetivarse necessita contar com uma base ou apoio normativo às leis e regras que emanam do Estado, ou seja, é necessário fuma cultura política participativa (BAQUERO, 2006).

$\mathrm{Na}$ perspectiva da cultura política, a forma como os cidadáos percebem e atuam no sistema político ajuda, ou não, a solidificar uma democracia. Desse modo, estudar atitudes, valores, crenças, ideais e experiências que predominam em uma dada sociedade em relação ao sistema político é um passo importante nessa direção.

- Rute Vivian Angelo Baquero é Pesquisadora do Núcleo de Pesquisa sobre América Latina (NUPESAL) da Universidade Federal do Rio Grande do Sul (UFRGS). E-mail: rutevivianb@gmail.com.

- Marcello Baquero é Professor do Programa de Pós-Graduação em Ciência Política da UFRGS. E-mail: marcelo.baquero@ufrgs.br.

\section{Referências}

ALMOND, Gabriel; POWELL JR, G. Bingham; DANTON, Russell; STROM, Kaare. Comparative politics today: a world view. Pearson/Longman: Scott, Foresman and Company, 2008.

ALMOND, Gabriel; VERBA, Sidney (Orgs.). The civic culture revisited: political attitudes and democracy in five nations. Londres: Sage, 1989.

ALMOND, Gabriel; VERBA, Sidney. The Civic Culture: Political attitudes and democracy in five nations. Boston: Little Brown, 1963. 
AMES, Barry; POWER, Timothy J. Parties and governability in Brazil. In: WEBB, Paul; WHITE, Stephen (Eds). Party politics in new democracies. Oxford: Oxford UP, 2006, p. 179-212.

ARISTÓTELES. A política. Rio de Janeiro: Tecnoprint, 1990.

AVELINO FILHO, George. Política e politicas sociais no Brasil: um estudo sobre a Previdência. 1991. 116 f. Dissertação (Mestrado em Sociologia) - Faculdade de Filosofia, Letras e Ciências Humanas, Universidade de São Paulo, São Paulo, 1991.

BAQUERO, Marcello. Una nueva gramática social en la poliarquía brasileña: la cultura política y capital social. Revista Venezolona de Ciência Política, Mérida, n. 26, p. 131-153, jul.-dez. 2004.

BAQUERO, Marcello (Org.). Reinventando a sociedade na América Latina: cultura política, gênero, exclusão e capital social. Porto Alegre: Universidade, 2001.

BAQUERO, Marcello. O papel dos adolescentes no processo de construção democrática no Brasil: Um estudo preliminar de socialização política. Porto Alegre: Cadernos de Ciência Política Universidade Federal do Rio Grande do Sul, 1997.

BECK, Paul A.; JENNINGS, M. Kent. Pathways to participation. American Political Science Review, v. 76, n. 1, p. 94-108, 1982.

BLAIR, Harry. Jump-starting Democracy: Adult Civic Education and Democratic Participation in Free Countries. Democratization, Londres, v. 10, n. 1, p. 53-76, 2003. BOBBIO, Norberto. Teoria geral da política: a filosofia política e asliçôes dos clássicos. Rio de Janeiro: Campus, 2000.

BOGAARDS, Matthijs. How to classify hybrid regimes? Defective democracy and electoral authoritarianism. Democratization, v. 16, n. 2, p. 399-423, 2009.

CARRANO, Paulo C. Jovens e participação política. In: SPÓSITO, Marilia P. (Coord.). Juventude e Escolarização (1980-1998). Brasília: Mec/Inep/Comped, 2002. p. 185-202.

CARVALHO, José M. Mandonismo, coronelismo, clientelismo. Dados, Rio de Janeiro, v. 40, n. 2, p. 229-250, 1997.

CARVALHO, José M. Rui Barbosa e a Razão Clientelista. Dados, Rio de Janeiro, v. 43, n. 1, p. 83117, 2000.

DAMATTA, Roberto. Reflexóes sobre o público e o privado no Brasil. Caderno de Ciências Sociais, Belo Horizonte, v. 83, n. 3, p. 51-62, abr. 1993.

DINIZ, Eli. Voto e máquina politica: patronagem e clientelismo no Rio de Janeiro. Rio de Janeiro: Paz e Terra, 1982.

DRUCKER, Peter. Sociedade pós-capitalista. São Paulo: Pioneira, 1993.

DWYER, Tom; et al. Sociology of Youth in the BRIC countries. No prelo, 2014.

ECKSTEIN, Harry. Division and Cohesion in Democracy: a Study of Norway. Princeton: Princeton University Press, 1966.

FAORO, Raymundo. Os donos do poder. Rio de Janeiro: Globo, 1989.

FLANAGAN, Constance; SHERROD, Lonnie. Youth political development: an introduction. Journal of Social Issues, v. 54, n. 3, p. 447-456, 1998.

FREIRE, Paulo; SHOR, Ira. Meao e ousadia - o cotidiano do professor. Rio de Janeiro: Paz e Terra, 1986.

GADOTTI, Moacir. Educação e poder: introdução á pedagogia do conflito. São Paulo: Cortez, 1985.

GARAY, María; SCHVARTZMAN, Mauricio. El joven dividido: la educación e los límites de la conciencia cívica. Asunción, Paraguay: Centro Interdisciplinario de Derecho Social y Economía Política (CIDSEP), 1987. 
GENTILLI, Pablo. Qual educação para qual cidadania? Reflexôes sobre a formação do sujeito democrático. In: AZEVEDO, José de. et al. (Orgs.). Utopia e democracia da educação cidadâ. Porto Alegre: Editora da Universidade/ UFRGS, 2000.

HOLANDA, Sérgio B. Raizes do Brasil. Rio de Janeiro: José Olímpio, 1936.

IBGE. Instituto Brasileiro de Estatística e Geografia. Dados Censo 2010. 2010.

IEL/CNI. Pesquisa Política. Instituto Euvaldo Lodi, 2010.

JOHN, P.; HALPERN, D.; MORRIS, Z. Can citizenship education generate social capital? The influence of family, school, and curriculum on political knowledge, efficacy and interest, and on voluntary activities and trust, among 15-16 year olds. Cambridge: Social and Political Sciences, University of Cambridge, Free School Lane, 2001.

MAINWARING, Scott. Sistemas partidários em novas democracias: o caso do Brasil. Rio de Janeiro: Editora FGV, 2001.

MAINWARING, Scott; SCULLY, Timothy. Introduction: party systems in Latin America. In: MAINWARING, Scott; SCULLY, Timothy (Eds). Building democratic institutions: parties and party systems in Latin America. Stanford: Stanford University Press, 1995. p. 1-34.

MENDEZ, María Cristina de. et al. El processo educativo venezolano: visión del Proyecto Venezuela. Caracas: Fundacredesa, 1989.

MILBRAITH, Lester; GOEL, Madan Lal. Political participation. Chicago: Rand McNally, 1977.

NAZZARI, Rosana Katia. Socialização política e construção da cidadania no Paraná - 1993-1994. 1995. Dissertação (Mestrado em Ciência Política), Universidade Federal do Rio Grande do Sul, Porto Alegre, 1995.

NUNES, Edson. A Gramática Politica do Brasil: clientelismo e insulamento Burocrático. Rio de Janeiro: Jorge Zahar Editores, 1997 [1978].

NUPESAL. Banco de Dados: Pesquisa de Cultura Política de juventude em Porto Alegre. Porto Alegre: 2002.

NUPESAL. Banco de Dados: Pesquisa de Cultura Política de juventude em Porto Alegre. Porto Alegre: 2004.

PAYNE, J. Mark et al. Democracies in development: politics and reform in Latin America. Baltimore: John Hopkins University Press, 2002.

PLATÃO. A república. São Paulo: Atena, 1955.

PNUD. Atlas de Desenvolvimento Humano no Brasil. ONU, 2003.

PUTNAM, Robert D. Comunidade e democracia: a experiência da Itália moderna. Rio de Janeiro: Fundação Getúlio Vargas, 1996.

PUTNAM, Robert D. Bowling Alone: The Collapse and Revival of American Community. Nova Iorque: Simon \& Schuster, 2000.

REIS, Elisa P. Governabilidade e solidariedade. In: VALADARES, Lúcia; COELHO, Magda (Orgs.). Governabilidade e pobreza no Brasil. Rio de Janeiro: Civilização Brasileira, 1995. p. 49-64.

RIFKIN, Jeremy. Where do we go from here? In: Colloquium on Education and Democracy, USAID, Washington D.C., 1999.

RODRÍGUEZ, Ernesto. 1987. Participación juvenil y la democratización en el Cono Sur. Montevideo, Uruguay: Centro Latinoamericano sobre Juventud, 1987.

RODRIGUEZ, Ernesto. Iuventud y democracia en América Latina: Apuntes preliminares para una perspectiva comparada. Mitos, certezas y esperanzas: Tendencias de las investigaciones en América Latina. Montevideo, Uruguay: Centro Latinoamericano sobre Juventud, 1989. 
SAMUELS, David. Determinantes do voto partidário em sistemas eleitorais centrados no candidato. Dados, Rio de Janeiro, v. 40, n. 3, p. 493-533, 1997.

SÁNCHEZ-PARGA, José. Transformaciones del conflicto, decline de los movimientos sociales y teoria del desgobierno. Ecuador Debate, Quito, n. 53, p. 19-39, ago. 2001.

SANDOVAL, Mario Manríquez. Jóvenes del siglo XXI: sujetos y atores en una sociedad en cambio. Santiago: Ediciones UCSH, 2002.

SCHIMDT, João P. Juventude e política no Brasil: a socialização política dos jovens na virada do milênio. Santa Cruz do Sul: EDUNISC, 2001.

SIEGEL, Roberta S. Political learning in adulthooa: a source-book of theory and research. Chicago: University of Chicago Press, 1989.

SOUZA, Ayda Connia de. Socialização política: a família e a escola na formação das atitudes políticas dos adolescentes de Porto Alegre. 1983. 264 f. Dissertação (Mestrado em Ciência Política) Programa de Pós-Graduação em Ciência Política, Universidade Federal do Rio Grande do Sul, Porto Alegre, 1983.

SOUZA, Maria do C. Estado e partidos políticos no Brasil (1930 a 1964). São Paulo: Alfa-Omega, 1976.

SPOSITO, Marília Pontes; CORTI, Ana Paula. A pesquisa sobre juventude e os temas emergentes. In: SPOSITO, Marília Pontes (Org.). Juventude e escolarização (1980-1998). Brasília: MEC/INEP/COMPED, 2002.

SPOSITO, Marília. Os jovens no Brasil: desigualdades multiplicadas e novas demandas políticas. São Paulo: Ação Educativa, 2003.

STOLLE, Dietlind; HOOGHE, Marc. Preparing for the Learning School of Democracy: The effects of Youth and Adolescent Involvement on Value Patterns and Participation in Adult Life. In: 98th Annual Meeting of the American Political Science Association, 98, Boston, 29 ago./10 set. 2002.

TOCQUEVILLE, Alex. A democracia na América. 3. ed. Belo Horizonte: Itatiaia, 1977.

VILLEGAS-REIMERS, Eleonora. Educación para la democracia en el contexto latinoamericano. In: Primer Seminario Internacional Educación para la Democracia, 1, Organización de los Estados Americanos (OEA), Asunción - Paraguay, 04-06 out. 1995.

LEAL, Victor. Coronelismo, Enxada e Voto. Rio de Janeiro: Forense, 1978.

WEBER, Max. Economia e Sociedade: fundamentos da sociologia compreensiva. 2 v. Brasília: Ed. da Unb, 2004. 